\title{
Forecast of power generation and heat production from renewable energy sources
}

\author{
Tadeusz Pydych ${ }^{1}$, Mateusz Szydłowski ${ }^{1}$, and Janusz Sowiński ${ }^{1, *}$ \\ ${ }^{1}$ Czestochowa University of Technology, Faculty of Electrical Engineering, 42-200 Czestochowa, \\ Poland
}

\begin{abstract}
The share of renewable energy sources (RES) in the end use of energy in the UE will increase from the present level of about $25 \%$ to $50 \%$ in 2030 according to the assumptions of the European Commission. In Poland the RES Act was passed in 2015. The act defines mechanisms and instruments for supporting the production of electricity and heat from renewable energy sources. Statistics (2003-2014) of electricity generation and heat production from RES in Poland were used in the research. Because of amendments to regulations connected with promoting RES and the emissions trading system (ETS) as well as the uncertainty associated with further directions of the energy and environmental policy, generation of electricity and heat based on the use of RES must be modelled while taking risk into account. A number of dynamic processes incorporating random events may be modelled by stochastic equations using Ito calculus. By applying Euler's method to solve stochastic differential equations (SDE), it is possible to simulate the development of the use of renewable energy carriers in electricity generation and heat production in the future.
\end{abstract}

\section{Introduction}

Current interest in renewable energy sources (RES) is largely due to the targets of the EU policy on energy generation and environment [1], but it also results from the fact that conventional energy sources, such as coal, oil and natural gas are running out $[8,10]$. Besides, economic growth typically causes increase in demand for energy, including renewable energy, which has a significantly less detrimental impact on the environment, especially with respect to the greenhouse effect, than energy obtained from fossil fuels [9]. By using locally available sources, renewable energy boosts development of distributed power generation. The fact that resources are located at a short distance from consumers reduces the cost of energy transmission in two ways - it eliminates costly investment in transmission lines and prevents energy losses. On the other hand, it requires the strengthening and development of distribution lines, including investment in the smart grid. A dynamic development of innovative technologies has to be accompanied by stable operation of the power system.

The changing energy market calls for a strategy that will ensure energy security in Poland $[5,6]$. Measures are taken in order to determine as precisely as possible the role of

\footnotetext{
* Corresponding author: jansow@el.pcz.czest.pl
} 
Polish coal in the future and to predict a development of RES. This in turn implies that the energy market, including the power market, will be undergoing transformation.

Utilizing RES is at the moment the key point of all the activities aimed to reduce emissions in electrical energy generation and consumption of fossil fuels, especially coal and lignite. It is believed that further technological progress will increase efficiency of energy generation from RES and its cost will be lower [12]. Due to EU policies promoting RES [1] and imposing the emission trading system (ETS), renewable energy is becoming increasingly popular as a target of future investments. The growth of RES is not however completely unobstructed - the area of land where biomass can be grown is limited, there are environmental constraints (other than pollutant emission), and the infrastructure is insufficient $[3,4]$.

Until recently, the most important mechanism for supporting renewable energy producers in Poland was the system of energy certificates and sales tax exemption. The RES Act has modified this system by introducing auctions and solutions for prosumers.

According to the government's announcement, the amount of renewable energy purchased obligatorily in 2017 will not be $20 \%$ of total purchased energy as was stipulated in the Act, but only $16 \%$, including $15.5 \%$ of green certificates energy and $0.5 \%$ of blue certificates energy (i.e. energy sold by agricultural biogas plants). Producers of nonrenewable electrical energy are obliged to buy green certificates at the stock exchange and submit them to Energy Regulatory Office, or alternatively, they have to pay a fee. Excessive supply of green certificates negatively impacts their price at the stock exchange: at the beginning of 2014 the price of a green certificate was $250 \mathrm{PLN} / \mathrm{MWh}$ and in August 2016 it was 56 PLN/MWh, which is almost an $80 \%$ drop. Withdrawing the support for renewable energy by diminishing the value of green certificates and at the same time decrease in energy prices puts investors into a disadvantage.

In July 2016 the so called distance act was passed, on which the minimal distance between a wind plant and houses or protected areas is to be ten times greater than the height of a wind turbine. The new regulation threatens both new projects, rendering most of them impossible to implement as well as existing wind plants, increasing taxes on them.

The amendment of the act on renewable energy passed on the 1st of July 2016 introduced new rules of settling accounts with prosumers by means of discounts, taking into account the balance between energy input into the grid, energy consumed and energy stored by a prosumer in the period of one year.

\section{Statistics of electricity generation and heat production from RES in Poland}

The present research uses the statistical report compiled by the Polish Central Statistical Office (GUS) "Energy from renewable sources", published in yearbooks [2]. The statistical data published by GUS [2] cover chronological data sets from the years 2003-2014. Sources regarded as RES include those exploiting the force of wind, sunlight, geothermal energy, sea waves, currents, tides and energy produced from solid biofuels, biogas and liquid biofuels as well as energy collected from natural environment by heat pumps.

For the calculations, statistics were used regarding electricity generation in GWh and heat production in TJ from renewable energy carriers in the years $2003 \div 2014$. The statistics include chronological data sets regarding total production and production broken by the following carriers: water (power plants with capacity below $1 \mathrm{MW}$, between $1 \mathrm{MW}$ and $10 \mathrm{MW}$, and above $10 \mathrm{MW}$ ), wind, solid biofuels, biogas (including biogas from landfill sites, from sewage treatment plants and other biogas), bioliquids and solar energy. 


\subsection{Obtaining primary energy from RES}

The share of renewable energy in total primary energy has been increasing in the recent years in Poland, with the variation in the amount of total primary energy obtained being relatively small. The share of renewable energy in total primary energy in the years 20072014 is presented in Table 1, and the structure of renewable energy sources in 2007 and in 2014 is presented in Fig.1. Of all the RES, liquid and solid biofuels by far exceed other carriers, wind energy is rapidly increasing and hydropower is slightly decreasing.

Table 1. Share of renewable energy in total primary energy in the years 2007-2014 (Source: GUS [2])

\begin{tabular}{|l|c|c|c|c|c|c|c|c|}
\hline Item & $\mathbf{2 0 0 7}$ & $\mathbf{2 0 0 8}$ & $\mathbf{2 0 0 9}$ & $\mathbf{2 0 1 0}$ & $\mathbf{2 0 1 1}$ & $\mathbf{2 0 1 2}$ & $\mathbf{2 0 1 3}$ & $\mathbf{2 0 1 4}$ \\
\hline $\begin{array}{l}\text { Total primary energy } \\
\text { [TJ] }\end{array}$ & 3040160 & 2985356 & 2816880 & 2824028 & 2882363 & 3038921 & 3006461 & 2853825 \\
\hline $\begin{array}{l}\text { RES primary energy } \\
\text { [T] }\end{array}$ & 203141 & 226788 & 253352 & 287313 & 312148 & 355259 & 356693 & 337659 \\
\hline $\begin{array}{l}\text { Share of RES energy } \\
\text { in total primary energy }\end{array}$ & $6.7 \%$ & $7.6 \%$ & $9.0 \%$ & $10.2 \%$ & $10.8 \%$ & $11.7 \%$ & $11.9 \%$ & $11.8 \%$ \\
\hline
\end{tabular}
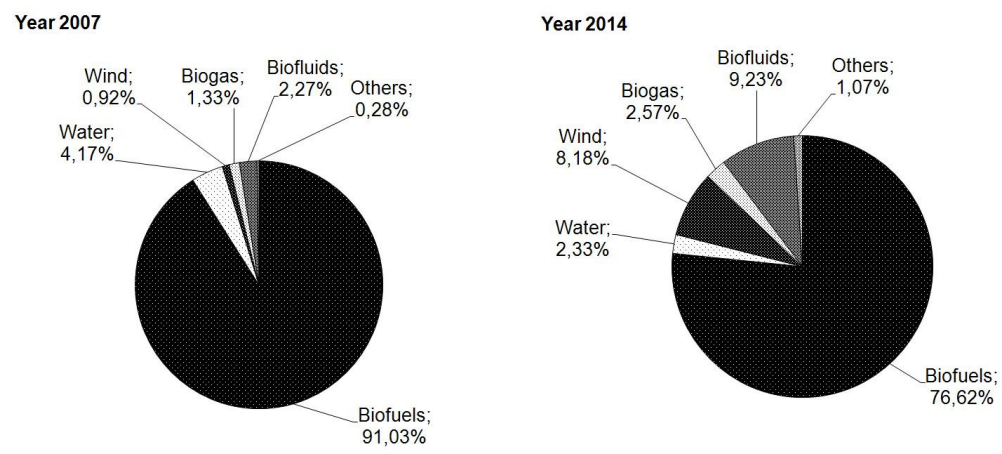

Fig. 1. Structure of renewable energy sources in 2007 and 2014 [2]

\subsection{Generation of electrical energy from renewable sources}

The calculations presented below are based on the statistics on electrical energy generation (in GWh) and heat generation (in TJ) from RES in the years 2003-2014. The statistics include chronological series of data on total generation and are divided into the following sources: water (hydroelectric plants of power below $1 \mathrm{MW}$, from $1 \mathrm{MW}$ to $10 \mathrm{MW}$ and above $10 \mathrm{MW}$ ), wind, solid biofuels, biogas (including biogas from landfill, from sewage treatment plants and other), bioliquids and solar energy. Generation of electrical energy in the period 2003-2014 is presented in Table 2 and in Fig. 2, and its structure in 2003 and in 2014 is shown in Fig. 3. 
Table 2. Electricity generation from renewable energy sources in the years 2003-2014 [GWh] (Source: GUS [2])

\begin{tabular}{|c|c|c|c|c|c|c|c|c|c|c|c|c|}
\hline Item & 2003 & 2004 & 2005 & 2006 & 2007 & 2008 & 2009 & 2010 & 2011 & 2012 & 2013 & 2014 \\
\hline Total & 2,250 & 3,074 & 3,848 & 4,291 & 5,429 & 6,606 & 8,679 & 10,889 & 13,137 & 16,879 & 17,066 & 19,842 \\
\hline $\begin{array}{l}\text { Water } \\
\text { of which power plants }\end{array}$ & 1,671 & 2,082 & 2,201 & 2,043 & 2,352 & 2,152 & 2,375 & 2,920 & 2,331 & 2,037 & 2,439 & 2,182 \\
\hline below $1 \mathrm{MW}$ & 242 & 273.5 & 358.2 & 247.9 & 306.3 & 290.2 & 292.2 & 516 & 307 & 320.7 & 351.9 & 322 \\
\hline between 1 and $10 \mathrm{MW}$ & 431 & 616.9 & 504.2 & 566.6 & 658.1 & 605.4 & 627.9 & 667.2 & 636.1 & 619.5 & 645.3 & 565 \\
\hline above $10 \mathrm{MW}$ & 998 & 1,191 & 1,339 & 1,228 & 1,388 & 1,257 & 1,455 & 1,738 & 1,388 & 1,097 & 1,442 & 1,296 \\
\hline Wind & 124 & 142.3 & 135.5 & 256.1 & 521.6 & 836.8 & 1,077 & 1,664 & 3,205 & 4,747 & 6,004 & 7,676 \\
\hline Solid biofuels & 399 & 768.2 & 1,400 & 1,833 & 2,360 & 3,365 & 4,904 & 5,905 & 7,148 & 9,529 & 7,932 & 9,160 \\
\hline of which co-firing & - & 620.5 & 1,236 & 1,645 & 2,126 & 2,963 & 4,661 & 5,593 & 6,389 & 7,239 & 3,929 & 4,510 \\
\hline $\begin{array}{l}\text { Biogas } \\
\text { of which }\end{array}$ & 56 & 82.2 & 111.3 & 160.1 & 195.2 & 251.6 & 319.2 & 398.4 & 451.1 & 565.4 & 689.7 & 816 \\
\hline biogas from landfill sites & 53 & 63.3 & 75.3 & 92 & 113.6 & 148.4 & 174.8 & 219.9 & 233.7 & 236.5 & 240.7 & 225 \\
\hline $\begin{array}{l}\text { biogas from sewage } \\
\text { treatment plants }\end{array}$ & 2 & 18.1 & 35.4 & 66.7 & 79.5 & 94.9 & 122.7 & 132.4 & 149.8 & 193.7 & 233.5 & 253 \\
\hline other biogas & 1 & 0.8 & 0.6 & 1.5 & 2.1 & 8.3 & 21.7 & 46.1 & 67.7 & 135.1 & 215.5 & 388 \\
\hline Bioliquids & - & - & - & - & - & - & 3 & 0.9 & 1.4 & 0.2 & 0.6 & 0 \\
\hline Solar energy & - & - & - & - & - & - & - & - & 0.2 & 1.1 & 1.5 & 7 \\
\hline
\end{tabular}

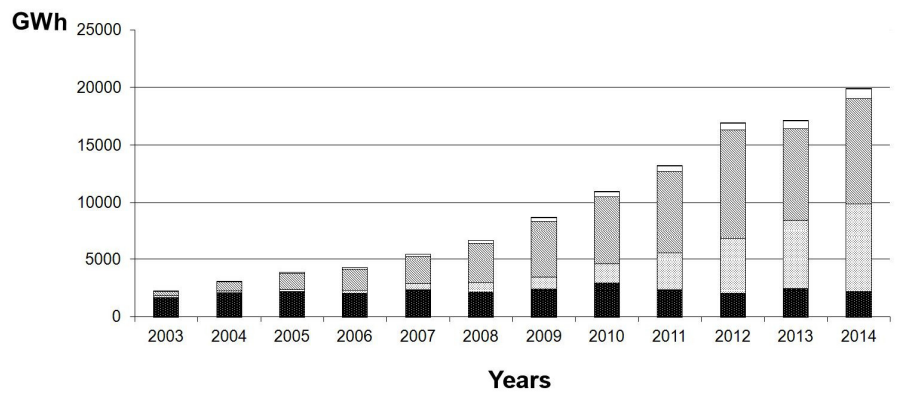

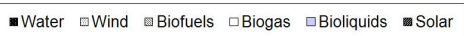

Fig.2. Electricity generation from renewable energy sources in the years 2003-2014 [2]

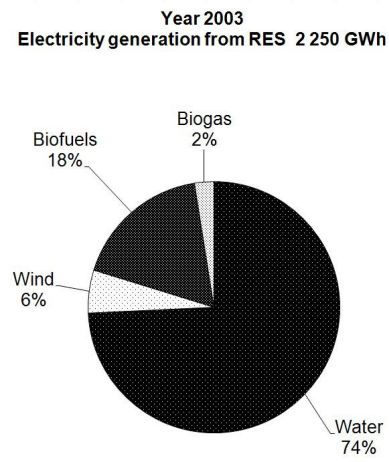

\section{Year 2014
Electricity generation from RES $19842 \mathrm{GWh}$}

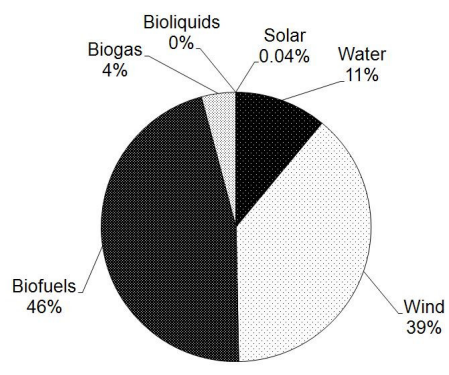

Fig. 3. Structure of electrical energy production from RES [2] 
A significant increase in renewable energy generation took place in the period 2003 2014. A comparison between the RES structure in 2003 and in 2014 indicates considerable changes as well: renewable energy obtained from solid biomass and wind significantly increased with the share of hydropower decreasing, despite the fact that the total volume of energy generated by hydroelectric plants increased by over $20 \%$. The share of bioliquids and solar energy in 2014 was much below $1 \%$.

\subsection{Production of heat from renewable sources}

The statistical data on heat production from renewable sources in the period 2003-2014 used in the calculations are presented in Table 3 and in Fig. 4.

Table 3. Heat production from RES in the period 2003-2014 [TJ] (Source: GUS [2])

\begin{tabular}{|l|c|c|c|c|c|c|c|c|c|c|c|c|}
\hline Item & $\mathbf{2 0 0 3}$ & $\mathbf{2 0 0 4}$ & $\mathbf{2 0 0 5}$ & $\mathbf{2 0 0 6}$ & $\mathbf{2 0 0 7}$ & $\mathbf{2 0 0 8}$ & $\mathbf{2 0 0 9}$ & $\mathbf{2 0 1 0}$ & $\mathbf{2 0 1 1}$ & $\mathbf{2 0 1 2}$ & $\mathbf{2 0 1 3}$ & $\mathbf{2 0 1 4}$ \\
\hline Total & 2766 & 2791 & 3589 & 3748 & 4706 & 6340 & 11270 & 12231 & 13452 & 19052 & 15988 & 14272 \\
\hline Solid biofuels & 2465 & 2242 & 2768 & 3049 & 4008 & 5414 & 10448 & 11479 & 13320 & 18840 & 15611 & 13973 \\
\hline $\begin{array}{l}\text { Biogas } \\
\text { of which }\end{array}$ & 301 & 549 & 821 & 699 & 698 & 926 & 817 & 751 & 131 & 212 & 377 & 299 \\
\hline $\begin{array}{l}\text { biogas from landfill } \\
\text { sites }\end{array}$ & 230 & 136 & 91 & 109 & 30 & 148 & 112 & 113 & 62 & 69 & 74 & 69 \\
\hline $\begin{array}{l}\text { biogas from sewage } \\
\text { treatment plants }\end{array}$ & 61 & 411 & 727 & 583 & 658 & 734 & 624 & 617 & 23 & 40 & 128 & 86 \\
\hline other biogas & 10 & 2 & 3 & 7 & 10 & 44 & 80 & 21 & 46 & 103 & 174 & 144 \\
\hline Bioliquids & - & - & - & - & - & - & 5 & 1 & 1 & 0 & 0 & - \\
\hline
\end{tabular}

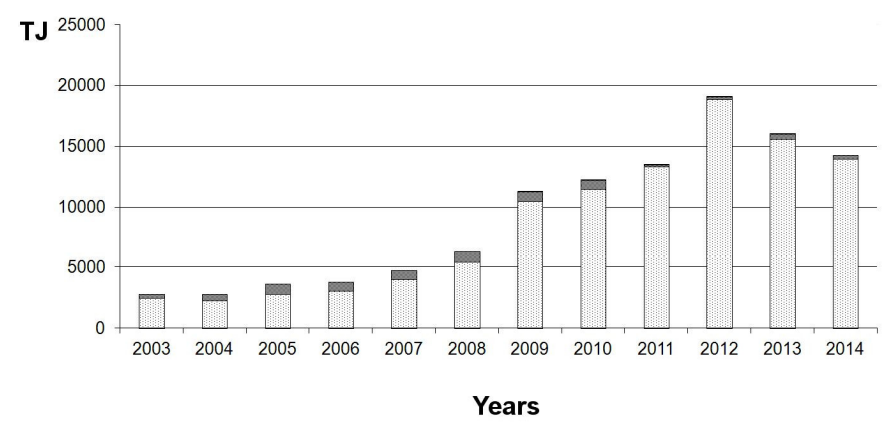

Biofuels @Biogas Bioliquids

Fig.4. Heat production from RES in the period 2003-2014 [2]

In the recent years heat production from RES rose dynamically. The greatest increase occurred in 2012 - by $38.7 \%$ with respect to 2011 .

The structure of renewable sources used in heat production in two selected years is presented in Fig.5. The most popular renewable energy carrier is solid biofuel.

Directive 2009/28/EC stipulates that Poland obtains a $15 \%$ share of renewable energy in total gross end-use energy consumption in 2020. It is a realistic target, considering the fact that in 2014 the share of renewable energy in total gross energy end-use consumption was $11.8 \%$. 

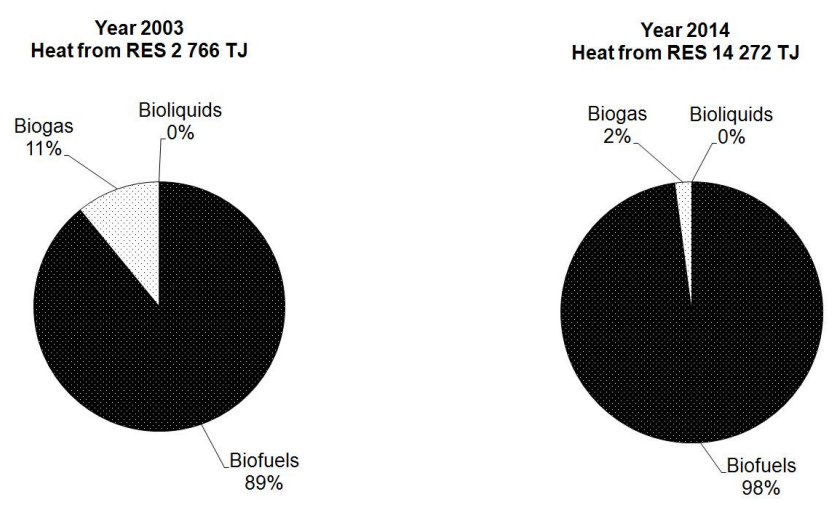

Fig. 5. Structure of heat production from RES in 2003 and in 2014 [2]

\section{Dynamic processes modelling}

A number of dynamic processes with random errors in economy and in power industry can be modelled by means of stochastic equations, such as the Ito equations [11]. They provide a powerful tool for the analysis of real economic phenomena and they have been fruitfully applied for modelling processes in power industry as well. When the stochastic differential equations are solved by means of Euler's method [7], it is possible to simulate utilization of RES for electrical energy and heat generation in the future.

A stochastic process with a number of continuous-time variables can be represented by means of stochastic differential equations (SDE) of the following general form:

$$
d X_{t}=F\left(t, X_{t}\right) d t+G\left(t, X_{t}\right) d W_{t},
$$

where: $X$ - the state variable, $W$ - the Wiener process (Brownian motion) variable, $F-$ the trend-determining function, $G$ - the diffusion function.

It is possible to define special variants of the model on the basis of the general formula (1). The simplest variant is a linear trend model with a random Brownian motion (BM) component. This variant includes two components: deterministic and random:

$$
d X_{t}=A(t) d t+V(t) d W_{t},
$$

Another variant is the model of relative variation in the state variable with a random component represented by geometric Brownian motion (GBM):

$$
d X_{t}=B(t) X_{t} d t+V(t) X_{t} d W_{t},
$$

The variability of the random component can be modelled as constant elasticity of variance $(\mathrm{CEV})$ :

$$
d X_{t}=B(t) X_{t} d t+V(t) X_{t}^{\alpha(t)} d W_{t},
$$

A fundamental property of the CEV stochastic model is the possibility of determining the relationship between the state variable and its variability through the value of the exponent $\alpha(t)$.

Another variant of model (1) is known as SDE from Mean-Reverting Drift (SDEMRD):

$$
d X_{t}=S(t)\left(L(t)-X_{t}\right) d t+D\left(t, X_{t}^{\alpha(t)}\right) V(t) d W_{t},
$$

where: $S(t)$ - the mean reversion speed, $L(t)$ - the mean reversion level (i.e. long run average level). 
If the function $D\left(t, X_{t}^{\alpha(t)}\right)=1$ (from Eq. 5), then it is possible to transform the formula into the Hull-White/Vasicek (HWV) model:

$$
d X_{t}=S(t)\left(L(t)-X_{t}\right) d t+V(t) d W_{t}
$$

The simulation of RES utilization treated as the state variables $X_{t}$ consists in obtaining a numerical solution of the SDEs, for which Euler's method is proposed. Since the renewable sources are a group of correlated variables, the most suitable simulation model is GBM including a multidimensional vector of correlated random variables, as in the formula below:

$$
d X_{t}=\mu X_{t} d t+\sigma d W_{t}
$$

where: $\mu$ - the mean value of the variable $X_{t}, \sigma$ - the standard deviation of the variable $X_{t}$.

Correlations between variables are taken into account for the multidimensional vector of random variables in Wiener processes. The GBM model adequately represents phenomena following the commodity-exchange rules. In the model under scrutiny, the risk measure corresponds to the value of standard deviation $\sigma$. The model includes a deterministic component, representing the trend of the variable and a random component, in which the uncertainty measure is the standard deviation of the variable. Uncertainty is to be taken in its economic sense, whereas in the mathematical sense it would be the risk measure since the probability distribution of the variable is known.

\section{Forecast of electrical energy and heat generation from RES under risk}

Selected simulations of electricity generation and heat production from renewable carriers are presented in Fig. 6 and 7 and the structures of electricity generation and heat production in 2020 are presented in Fig. 8 and 9. The simulations for the future period 2015-2020 can be considered as the forecasts. The average values and standard deviations of variables $X_{t}$ in formula (7) have been estimated on the basis of historical sequences. Estimates of trend coefficients were limited in such a way that the particular simulations allow for achieving the basic objective for Poland, which is a $15 \%$ share of renewable energy carriers in the end demand.

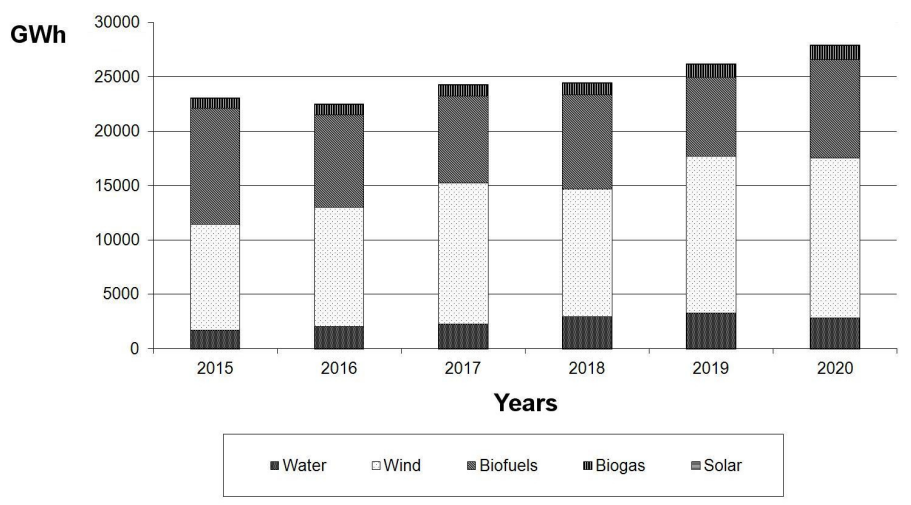

Fig.6. Selected simulation of electricity generation from RES in years 2015-2020 


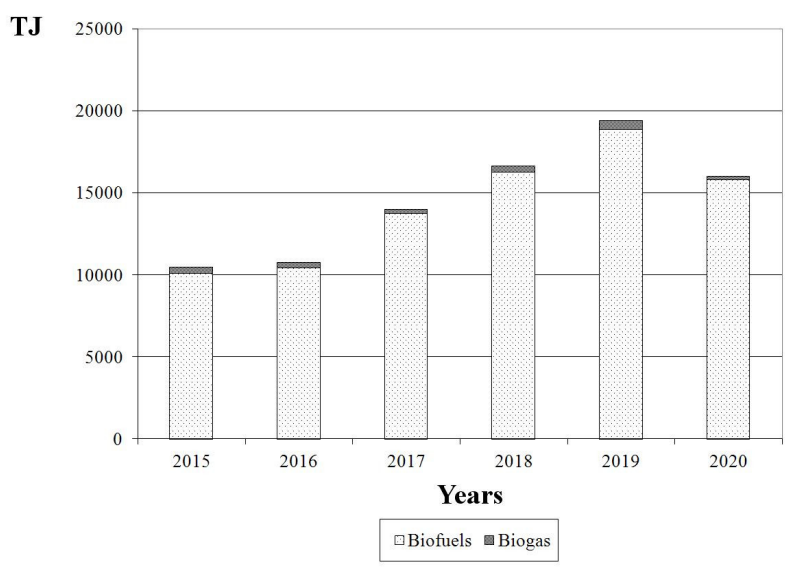

Fig.7. Selected simulation of heat production from RES in the years 2015-2020

Since the value of the standard deviation was estimated on the basis of RES utilization in the past period, the risk level was also assumed to be the same as in the past. If a greater value of the standard deviation is assumed, the risk level is also taken to be greater. A detailed discussion on risk quantification can be found e.g. in [11].

Electricity generation from RES $27884 \mathrm{GWh}$ in 2020

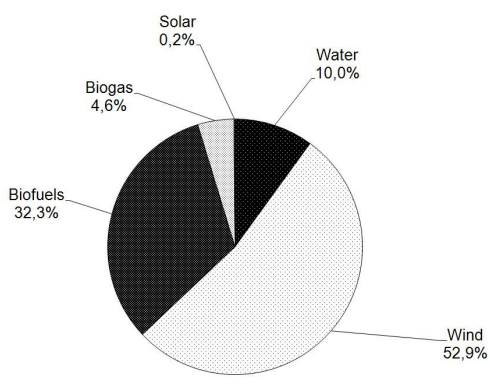

Fig.8. Selected simulation of the structure of RES utilized in electrical energy generation in 2020

\section{Conclusions}

Simulations of electricity generation and heat production from renewable carriers until 2020 were performed using Euler's method. The derived sequences should be treated as possible scenarios on condition that the trends observed on the RES market to date continue. Simulations are based on approximate solutions obtained from the GBM model including correlation among the variables (i.e. renewable energy carriers), represented by the Wiener processes.

The simulation results presented in Fig. 6 and 8 confirm the dynamic growth of the electricity production from RES. The increase in electricity production in 2020 is about $40 \%(27884 \mathrm{GWh})$ as compared with $2014(19842 \mathrm{GWh})$. The largest share in 2020 in the structure of electricity production is noted for wind power plants (approx. $53 \%$ ), followed by biofuels power plants (approx. $32 \%$ ) and hydropower plants (approx. $10 \%$ ). 
The simulation results of heat production from RES are presented in Fig. 7 and 9. Increase in heat production in 2020 is about $12 \%$ (16 $002 \mathrm{TJ})$ as compared with 2014 $(14272 \mathrm{TJ})$. The share of biofuels in the structure of heat production is about $99 \%$.

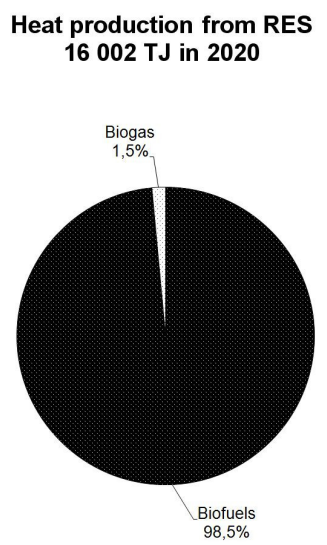

Fig.9. Selected simulation of the RES structure utilized in heat production in 2020

Different simulation sequences may be obtained by changing the assumptions about the development of variables in the future. For example, different results are obtained if the correlation among variables in the GBM model is not taken into account. Other scenarios will be produced if it is assumed that the behaviour of variables is determined by market rather than commodity-exchange mechanisms. Then, simulations should be performed by means of the mean-reverting drift model (SDEMRD) or the Hull-White/Vasicek model (HWV) [7].

A crude analysis has been carried out with regard to the impact of uncertainty about the environment of the model on the simulation results. Uncertainty connected with a number of factors - such as: the uncertainty concerning legal regulations regarding RES, energy and environmental policy of the EU and Poland, opportunities for obtaining renewable carriers, their prices, etc. - was modelled by introducing into equation (7) a random component, taking into account total risk quantified with the value of the standard deviation $\sigma$. The presented methodology of modelling processes in power engineering in the presence of risk seems to be a promising analytical tool, undoubtedly requiring further research. The risk measure corresponds to the value of standard deviation $\sigma$ in the models. The values of the standard deviation were estimated on the basis of RES utilization in the past period, that's why the risk level was also assumed to be the same as in the past. If a greater value of the standard deviation is assumed in the models, the risk level is also taken to be greater.

The world power industry has already changed a lot from the traditional model of monopoly towards competitive markets. The changes in the technology of energy and heat generation as well as continuous progress in lowering the investment cost of renewable energy legitimize the conclusion that in the future renewable energy technology should be competitive with respect to other technologies with high variable costs.

When it comes to evaluation of power generation technologies, their impact on the environment is becoming increasingly important. It can be suspected that the power industry will remain tightly connected to environmental issues in the future as well, which will inevitably lead to a new paradigm in power industry, advantageous both for economy and society. 


\section{References}

1. Directive 2009/28/EC of the European Parliament and of the Council of 23 April 2009 on the promotion of the use of energy from renewable sources.

2. Central Statistical Office of Poland (GUS), Energia ze źródet odnawialnych. Yearbooks 2003-2013 (Warsaw)

3. A. Gawlak, L. Poniatowski, Main directions of investment in the sector of electrical energy distribution, EPE 2014, DOI: 10.1109/EPE.2014.6839418

4. A. Gawlak, M. Kornatka, Comparative analysis of operating conditions in Polish medium-voltage and $110 \mathrm{kV}$ networks, Proceedings of The 8th International Scientific Symposium ELEKTROENERGETIKA 2015, Stará Lesná, Slovak Republic, pp.53-56

5. Polish Ministry of the Economy, Energy policy of Poland until 2030 (Warsaw 2009).

6. Polish Ministry of the Economy, National action plan for energy from renewable sources (Warsaw 2010)

7. B.K. Øksendal, Stochastic Differential Equations: An Introduction with Applications (Berlin Springer, 2003)

8. I. Marciniak, Światowe i unijne normatywne dokumenty a rozwój OZE w Polsce, Przegląd Elektrotechniczny, 90, 7 (2014)

9. J. Paska, T. Surma, Wyzwania dla Polski w świetle nowej polityki energetycznej Unii Europejskiej, Rynek Energii, 113, No.4 (2014)

10. J. Popczyk, Synergetyka, Przegląd Elektrotechniczny, No. 6 (2011)

11. J. Sowiński, Inwestowanie $w$ źródła wytwarzania energii elektrycznej $w$ warunkach rynkowych (WPCz, Częstochowa, 2008)

12. J. Sowiński, Koszty energii elektrycznej z odnawialnych źródeł energii, Przegląd Elektrotechniczny, 90, No. 8 (2014) 